\title{
Porphyrin and Phthalocyanines-Based Solar Cells: Fundamental Mechanisms and Recent Advances
}

\author{
Oyebanji Opeyemi a , Hitler Louis b,c,*, Chinanso Opara b , Oyebanji Funmilayo ${ }^{d}$, Thomas \\ Magu $\mathrm{c}, \mathrm{e}, *$
}

\begin{abstract}
ART ICLE INFO
Received: 15 Novomber 2018

Revised: 6 December 2018

Accepted: 23 December 2018

Available online: 6 January 2019

\section{KEYWOR D S}

Dye-sensitized solar cell

Porphyrin

Phthalocyanines

\section{A B S T R A C T}

A remarkable source of renewable energy is the Dye-sensitized solar cells (DSCs). However, the major limitation of power conversion efficiency (PCE) of devices is their inability to produce electricity using photons from the near infrared (NIR) spectral region. Some Metal-free organic sensitizers make use of strong electron donating or withdrawing moieties to tune the optical band gap to allow the absorption of lower energy wavelengths in charge transfer systems while porphyrins and phthalocyanines compounds are used to shift the Soret and $\mathrm{Q}$ bands toward lower energy absorption. Various molecules have been synthesized to improve and increase the power conversion efficiency of the compounds. This study review the structure of these compounds, working principles and their derivatives as recent advances have been carried out to improve the power efficiencies of the compounds.
\end{abstract}

GRA P H I C A L A B S T RACT

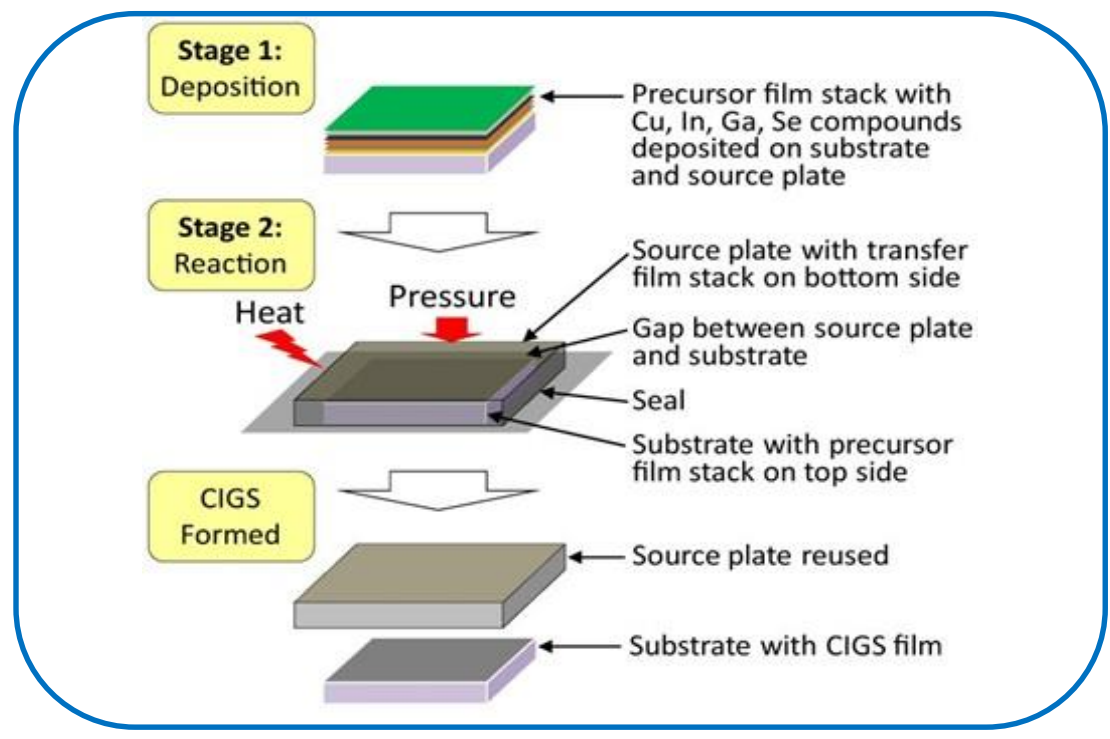

*Corresponding author's E-mail address: Louis@nanoctr.cn (H. Louis), thomasmagu@ iccas.ac.cn (T. Magu) Tel.: $+8619801310665$

a Department of Chemistry, University of Ilorin, Ilorin, Nigeria

b CAS Key Laboratory for Nanosystem and Hierarchical Fabrication, CAS Centre for Excellence in Nanoscience, National Centre for Nanoscience and Technology, University of Chinese Academy of Sciences, Beijing, China

${ }^{c}$ Department of Pure and Applied Chemistry, Faculty of Physical Sciences, University of Calabar, Calabar, Cross River State, Nigeria

${ }^{d}$ Department of Chemistry, Faculty of Physical Sciences, University of Ibadan, Ibadan, Nigeria

${ }^{e}$ CAS Key Laboratory of Green Painting, CAS Institute of Chemistry, University of Chinese Academy of Sciences, 100190 Beijing, China 


\section{Introduction}

An electrical device that uses both physical and chemical phenomenon in the direct conversion of light energy into electricity by the photovoltaic effect is called either a solar cell or photovoltaic cell [1]. It is a form of photoelectric cell defined as a device whose electrical characteristics such as current, voltage or resistance vary when exposed to light [2]. A very good source of this incredible supply of solar energy is the earth. The sun and an average star is a fusion reactor that has been burning for so many years. The amount of solar radiation striking the earth over a three-day period is equivalent to the energy stored in all fossil energy sources such that, it provides enough energy that can supply the world's needs for one year within the shortest period of time and more energy than our current population possesses, as estimated and shown in Figure 1 [3]. Solar energy is a natural resource that is inexhaustible and free but exploiting it is relatively a new idea. This is so because the first solar cell designed was made less than 30 years ago. The continuous growth of solar professional companies designing unique and specific solar power systems for homes makes solar power easy for domestic use. The emergence of transistors and semiconductor technology revitalized the efficiency of solar power; hence, several advantages are associated with photovoltaic solar power which makes it one of the most potential renewable energy sources in the world compared to other sources of power. Amongst these includes; [4] (a) It does not cause pollution, (b)none of its moving parts that could break down, (c) its maintenance is less expensive, (d) it does not require frequent monitoring or supervision, (e) its lifespan is about 20-30 years with less running costs and (f) it doesn't require the process of large-scale installation. Solar power generators can be used in homes, schools, or businesses, which have a fixed assembly size or land area that requires no extra development or expansion. Also, it can be used in a community that is still growing and developing, as the community grows more solar energy capacity will be added to the existing ones so that the community's needs could be satisfied. Most developing countries seek solar energy today, due to the fact that it is the fastest growing sector of the renewable energy market. Most houses, offices, firms etc. go without electricity as the sun sets during the day, thereby making solar power the obvious choice of energy. Governments are finding its modular, decentralized character, ideal for satisfying the electrical needs of thousands of remote places in different countries. It is much more practical than the extension of expensive power lines into remote areas, where people 
do not have sufficient finance to pay for conventional electricity supply. However, the amount of sunlight which varies greatly depending on geographical location, time of day, season and cost of equipment are some disadvantages of solar power [4]. The description of solar cells is basically described as photovoltaic, regardless of whether its source is from an artificial light or sunlight. They are used to detect photons or rays e. g. infrared detectors senses light or other electromagnetic radiation near the visible range of the electromagnetic spectrum or measuring light intensity. They are the building blocks of photovoltaic modules, otherwise known as solar panels. The operation of a photovoltaic (PV) cell requires 3 basic attributes (a) the absorption of light generating electron-hole pairs or exactions, (b) the separation of charge carriers of opposite types and (c) the separate extraction of those carriers to an external circuit.
Generally, solar cells are named after the semiconducting material that is used for construction which must have certain characteristics to absorb sunlight. In other to capture/harvest the sunlight that reaches the Earth's surface, cells could be accurately designed for such purpose, likewise, for those to be used in space can be optimized. Solar cells can be made of either a single or multiple junctions (which means one single layer of light-absorbing material or use multiple physical configurations respectively), so as to take advantage of mechanisms of various absorption and charge separation. Due to the effects of technologies, solar cells have been undergoing a series of development, hence they are classified into first, second and third generation cells. It is expected that the improvement in the applicability, efficiency and cost would be directly proportional to these generations as estimated by [5] in Figure 2 below.

\section{Types of Solar Cells and their}

\section{Fundamental Principles}

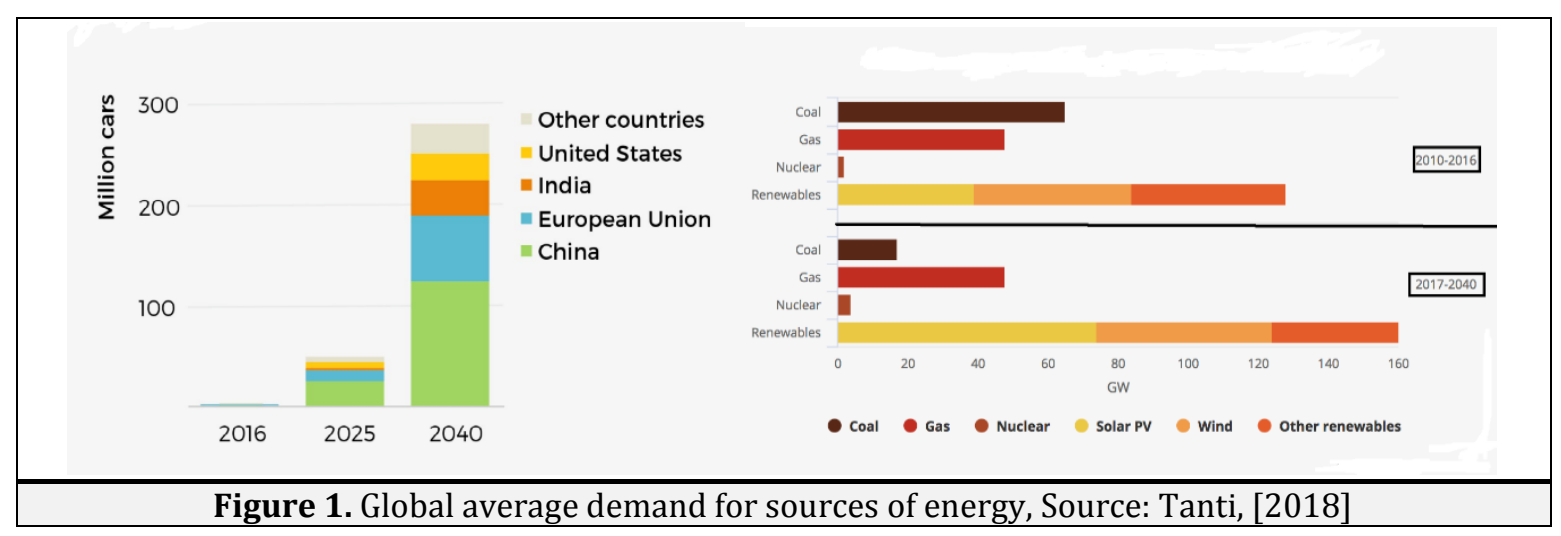




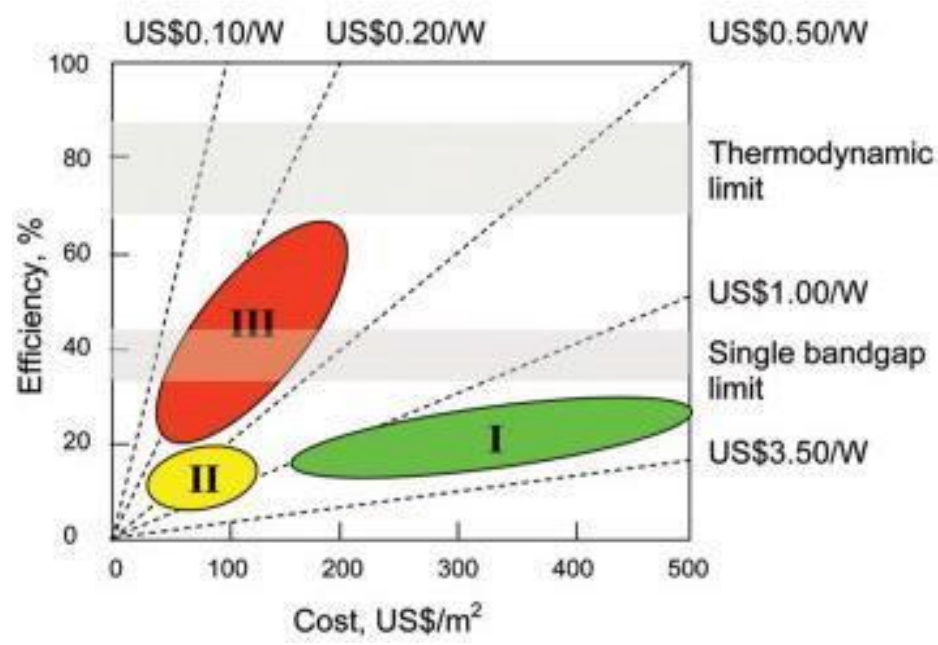

Figure 2. Cost and Efficiency ratio comparison between first, second and third generations of solar cells

The following are the different types of solar cells

\section{Biohybrid Solar Cell}

A biohybrid solar cell is a cell made using a combination of organic matter (photosystem I) and inorganic matter. A team of researchers at Vanderbilt University have explicitly completed works on biohybrid solar cells. They achieved the success of the entire process by making use of the photosystem I (a photoactive protein complex situated in the thylakoid membrane) so that the natural process of photosynthesis can be restored for the sole purpose of obtaining a higher efficiency in the conversion of solar energy. They (biohybrid solar cells) are a new type of renewable energy $[6,7]$. In the photosystem I, the multiple layers tend to gather photonic energy that will be converted into chemical energy, thereby creating a current that goes through the cell. The cell comprises of many same non-organic materials which can equally be found in other solar cells with the exclusion of the injected photosystem I complexes which are introduced and collected for several days in the gold layer. Afterwards, the photosystem I is made visible and a thin green film is observed to have appeared. The observed thin film is responsible for assisting and improving the process of energy conversion. Though, the biohybrid cell is still in the research phase. This team from Vanderbilt University instigated conducting research on the photosynthesis when their entire focus dwelt on the photosystem I protein. When they realized the availability and how efficient the protein was at solar conversion, they generated new ideas on how to fit in 
and improve subsequent technologies. Spinach served as their source for the photosystem I, were Thylakoid membranes were isolated and a process of purification to separate the photosystem I from the thylakoid membrane was carried out. The result obtained from their research was brilliant because it impressively enhanced the electrical current (up to 1000 times greater than those previously observed from other solar cells). In view of this achievement, the team has been recruiting some group of undergraduate engineers to aid build the first prototype of the biohybrid solar cell. Of course, they have successfully come up with a second design of the protein complex called the photosystem II.

\section{Buried Contact Solar Cell}

This solar cell is a commercial solar cell technology with high efficiency based on a plated metal contact inside a laser-formed groove. It overcomes most of the disadvantages associated with screenprinted contacts which allow buried contact solar cell to have high performance up to $25 \%$ better than commercial screen-printed solar cells. For this key feature (High efficiency) of this type of solar cell to be obtained, the metal is buried in a laserformed groove inside the silicon solar cell. This allows for a large metal height-width aspect ratio. In turn, a large metal contact aspect ratio, in turn, allows a large volume of metal to be used in the contact finger, without having a wide strip of metal on the top surface. For that reason, while still retaining a high transparency, a high metal aspect ratio allows a large number of closely spaced metal fingers. For instance, on a large area device, a screen printed solar cell may have shading losses as high as 10 to $15 \%$, while in a buried contact structure, the shading losses will only be 2 to $3 \%$. For the lower shading losses, they allow low reflection and thus higher short-circuit currents. In addition to good reflection properties, the buried contact technology also allows low parasitic resistance losses as a result of its high metal aspect ratio, its fine finger spacing and its plated metal for the contacts. An emitter resistance is reduced in a buried contact solar cell since narrower finger spacing dramatically decreases the emitter resistance losses, the metal grid resistance is also low subsequently the finger resistance is decreased by the large volume of metal in the grooves and with the aid of copper which has a lower resistivity than the metal paste used in screen printing. Also, the contact resistance of a buried contact solar cell is lower than that in screen-printed solar cells due to the formation of a nickel silicide at the semiconductor-metal interface and the large metal-silicon contact area. Generally, these 
reduced resistive losses permit large area solar cells with high FFs. When compared to a screen-printed cell, the metallization scheme of a buried contact solar cell also improves the cell's emitter. In other to minimize resistive losses, the emitter region of a screen-printed solar cell is very heavily doped and results in a "dead" layer at the surface of the solar cell. Meanwhile, emitter losses are low in a buried contact structure, the emitter doping can be enhanced for high open-circuit voltages and short-circuit currents. Additionally, a buried contact structure includes a self-aligned, selective emitter, which reduces the contact recombination and also contributes to high open-circuit voltages. The benefits of efficiency for the buried contact technology provide significant cost and performance. In terms of $\$ / W$, the cost of a buried contact solar cell is as equal as a screen-printed solar cell. On the other hand, due to the inclusion of certain area-related costs as well as fixed costs in a PV system, a higher efficiency solar cell technology results in lower cost electricity. An additional advantage of buried contact technology is that it can be used for concentrator systems [8].

\section{Cadmium Telluride Solar Cell (CdTe)}

Cadmium telluride (CdTe) photovoltaic describes a photovoltaic (PV) technology that is based on the use of cadmium telluride, a thin semiconductor layer designed to absorb and convert sunlight into electricity [13]. Cadmium telluride PV is the only thin-film technology with lower costs than conventional solar cells made of crystalline silicon in multi-kilowatt systems $[9,10,11]$. On a lifecycle basis, CdTe PV has the smallest carbon footprint, lowest water use and shortest energy payback time of all solar technologies $[12,13,14]$. CdTe's energy payback period of less than a year enables for faster carbon reductions without short-term energy deficits. Cadmium's toxicity is an environmental concern and can be alleviated by the recycling of CdTe components at the end of their lifetime [15], though there are still uncertainties $[16,17]$ and the opinion of the public is uncertain towards this technology $[18,19]$. The effective use of these rare materials maybe a limiting factor in the near future to the industries that apply the knowledge of CdTe technology. The rare abundance of tellurium, of which telluride is the anionic form is similar to that of platinum in the earth's crust and contributes significantly to the module's cost [20]. CdTe photovoltaic is used in some of the world's largest power stations, such as the Topaz Solar Farm. With a share of $5.1 \%$ of worldwide PV production, CdTe technology accounted for more than half of the thin film market in 2013 [21]. Conversely, CdTe appears to be less toxic 
than elemental cadmium, at least in terms of acute exposure. This is not to say it is harmless. Cadmium telluride is toxic if ingested, if its dust is inhaled, or if handled wrongly (i.e., without adhering strictly to necessary safety precautions before usage), hence, it is the sixth most toxic compound known. Its toxicity is not only due to the presence of cadmium content but as studies have shown that the highly reactive surface of cadmium telluride quantum dots triggers extensive reactive destruction of oxygen in the cell membrane, mitochondria, and cell nucleus. In addition, the cadmium telluride films are usually recrystallized in a toxic compound of cadmium chloride. The manner of disposal and long-term protection of cadmium telluride is an issue in the large-scale commercialization of cadmium telluride solar panels that need to be addressed without delay. Serious efforts have been made to comprehend and overcome these issues. Researchers from the U.S. Department of Energy's Brookhaven National Laboratory discovered that largescale use of CdTe PV modules does not pose any risks to health and environment, and recycling the modules after usage resolves any environmental concerns. During their operation, these modules do not produce any pollutants, besides, by displacing fossil fuels, they offer great environmental benefits. Nevertheless, the European Union and China's approach towards the safety of CdTe is a strict one. Cadmium and its compounds are considered as toxic carcinogens in EU whereas China regulations allow $\mathrm{Cd}$ products for export only. The issue of regulating the use of Cadmium Telluride is presently being discussed in Europe. At present, the most common opinion been suggested is that the use of Cadmium Telluride in residential, industrial rooftops and installations does not pose a threat to environmental degradation [22].

\section{Concentrated PV Cell (CVP and HCVP)}

A Concentrating Photovoltaic (CPV) system changes the energy from light into electrical energy, which is similar to the conventional photovoltaic technology, but it makes use of an advanced optical system to obtain a maximum efficiency by focusing on a large area of sunlight in each cell. Different CPV designs exist, which can be differentiated by a concentration factor, such as high concentration (HCPV) and lowconcentration (LCPV). Concentrator photovoltaics (CPV) is a photovoltaic technology that produces electricity from sunlight. Contrary to the traditional photovoltaic systems, it involves the use of lenses and curved mirrors to focus on the light rays from the sun onto small, but very efficient, multi-junction (MJ) solar cells. 
Furthermore, CPV systems frequently use solar trackers and at times a cooling system to further increase their efficiency [23]. Researches and development are currently in progress so as to rapidly improve their effectiveness in the utility-scale segment and in areas of high solar insulation. The technology (CPV) has been in existence ever since the 70s. New technological developments required to facilitate CPV to influence viability and compete with traditional fossil fuel plants, such as coal, natural gas, and oil, when installed in different regions of the world with dry and sunny climates. Concentrating photovoltaic systems work by transforming solar light into electricity. Traditional rooftops solar modules depend on the same basic idea to generate electricity. A CPV system has an optical component, which "concentrates" significant amounts of light rays from the sun onto "multi-junction" solar cells. Particularly, High concentrating photovoltaic (HCPV) systems have the potential to become competitive in future. They own the highest efficiency of all current PV technologies, and a smaller photovoltaic array also decreases the balance of system costs. At present, CPV is not used in the PV rooftop segment and far less common than conventional PV systems [24]. The working principle of concentration photovoltaic (CPV) modules is similar to traditional PV modules, apart from the fact that they use optics to concentrate the sunlight rays onto solar cells that do not cover the whole module area. This concentration factor - in Semprius' case over 1,100 times - intensely moderates the amount of semiconductor required $(<\mathrm{Jsc}<42$ $\mathrm{mA} / \mathrm{cm}^{2}$ due to their increased absorption of Infra-red light. We attain an efficiency of $4.5 \%$ with no passivation layers applied. Previously reported efficiency results obtained by Harvard University were 2.2\% for a laser processed Black Silicon solar cell. Figure 2, hence the Future of Black Silicon. Sometimes, the electron simply recombines with a silicon atom, effectively wasting the energy provided by the photon. Recombination is proportional to the surface area of the silicon, and the needles on the surface of dark silicon increase the surface area so much that about half of the free electrons are "lost" during the process. Currently, a team of researchers led by assistant professor Hele Savin has made a drastic effort to proffer solution to the issue, and the results they obtained indicates that there is an increased value of efficiency with respect to black silicon cells by almost four percentage points, which is up to $22.1 \%$. The researchers were able to prove that their performance in real-life is still better, thanks to their ability to accept sunlight from lower angles, black silicon cells can gather three 
more percent of energy than a cell with the same nominal efficiency during the whole day. Savin and colleagues took the responsibility to frequently observe the process of recombination with the application of a thin aluminium film, acting like an electronic and chemical shield, on top of the nanostructures. They also joined all the metal contacts on the back side of the cell, so as to enhance absorption. These two changes show that only $4 \%$ of the freed up electrons recombined, as opposed to the previous 50\%. The new cell design is nevertheless likely not pushing this technology to its limit just yet since it made use of p-type silicon rather than the more durable n-type silicon.

\section{Copper Indium Gallium Selenide Solar Cells}

One of the most interesting and controversial materials in solar is CopperIndium-Gallium-Selenide or CIGS for short Figure 3 It was part of a solar thin-film-hype cycle where some CIGS companies such as MiaSolé, Nanosolar and Solyndra almost became household names. A copper indium gallium selenide solar cell (CIGS cell) is a thin film solar cell used to transform light rays from the sun into electric power. They are synthesized by depositing a thin layer of copper, indium, gallium and selenide on plastic backing or glass, along with electrodes on the front and back to collect current. This is because the material has a high absorption coefficient and intensely absorbs sunlight, a much thinner film is essential than that of other semiconductor materials. CIGS is one of the three mainstream thin-film PV technologies, the other two being amorphous silicon and cadmium telluride. Similar to these materials, CIGS layers are thin enough to be flexible, allowing them to be deposited on flexible substrates. On the other hand, as all of these technologies generally use hightemperature deposition techniques, the best performance typically comes from cells deposited on glass. With these, the performance is marginal compared to modern polysilicon-based panels. Since the adoption of recent advances in the lowtemperature deposition of CIGS cells has erased much of the difference in performance. It is best known as the material for CIGS solar cells a thin-film technology used in the photovoltaic industry [25]. Conversely, CIGS possess the advantage of being able to be deposited on flexible substrate materials, producing highly flexible, lightweight solar panels. Having discovered that improvements in efficiency have made CIGS an established technology among alternative cell materials.

Dye-Sensitized Solar Cell (DSSC) 
Dye Sensitized solar cells (DSSC), also sometimes referred to as dye-sensitized cells (DSC), are a third generation photovoltaic (solar) cell that converts any visible light from its source into electrical energy. This new class of advanced solar cell can be compared to artificial photosynthesis due to the fact that it illustrates similar phenomena of nature's absorption of light energy. Its invention was in 1991 by Professor Michael Graetzel and Dr Brian O’Regan at École Polytechnique Fédérale de Lausanne (EPFL), Switzerland and is often referred to as the Gräetzel cell; we also call it G Cell. DSSC is a disruptive technology that can be used to produce electricity in a wide range of light conditions irrespective of whether it is indoors or outdoors, allowing the user to convert both natural and artificial light into energy to power various kinds of electronic devices. A dye-sensitized solar cell (DSSC, DSC or DYSC) [26] is a lowcost solar cell that belongs to the group of thin film solar cells [27].

It is as a result of a semiconductor formed between an electrolyte and a photosensitized anode, a photoelectrochemical system. It has quite a number of interesting features, which includes; it is simple to make using conventional roll-printing techniques, is semi-flexible and semitransparent which offers a variety of uses not applicable to glass-based systems, and most of the materials used are relatively inexpensive.

In practice, it is difficult to eliminate quite a number of expensive materials, particularly ruthenium and platinum, and the liquid electrolyte presents a serious challenge to making a cell suitable for use in all weather. Though its conversion efficiency is less than the best thin-film cells, in theory, its price/performance ratio should be good enough to allow them to compete with fossil fuel electrical generation by attaining grid parity.

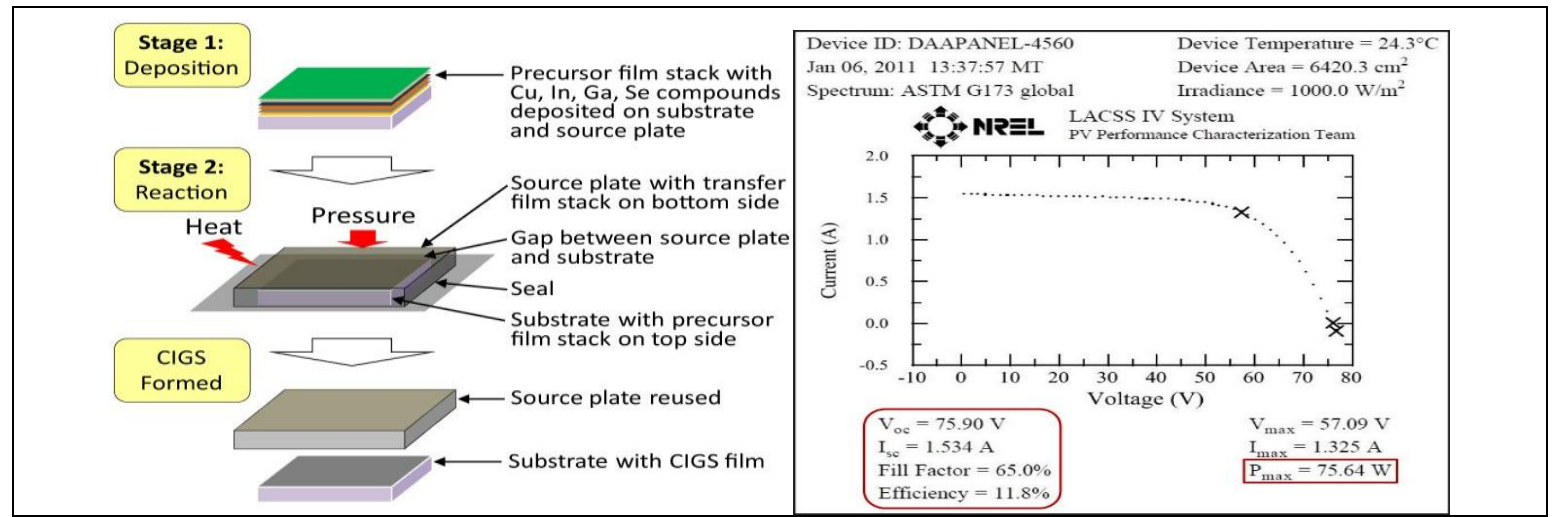

Figure 3. (a)Two-stage reactive transfer process for producing photovoltaic copper indium gallium selenide (CIGS) film. Cu: Copper. In: Indium. Ga: Gallium. Se: Selenium. (b) Light current-voltage (IV) curve measured by the National Renewable Energy Laboratory (NREL) on a $120 \times 60 \mathrm{~cm}^{2}$ CIGS module. 
Commercial applications, which were held up due to chemical stability problems are forecast in the European Union Photovoltaic Roadmap to significantly contribute to renewable electricity generation by 2020 [28].

\section{Gallium Arsenide Germanium Solar Cell (GaAs)}

Gallium arsenide is made up of two base elements; Gallium and Arsenic. Combining these two elements together, give rise to the aforementioned compound, which shows several interesting characteristics. In comparison with silicon, the semiconductor Gallium arsenide possesses greater saturated electron velocity and electron mobility. Hence, it can be said that a semiconductor is a material whose electrical conductivity falls between a conductor and an insulator; its ability to conduct electricity may vary depending on its temperature (that is when it is either cool or hot), thus numerous applications can be obtained from it. Another interesting characteristic shown by gallium arsenide is that, it is a direct band gap semiconductor. This illustrates that it can emit light efficiently. It is an III-V direct bandgap semiconductor with a zinc blende crystal structure. It is used in the manufacture of devices such as monolithic microwave integrated circuits, microwave frequency integrated circuits, infrared light- emitting diodes, solar cells, optical windows and laser diodes [29]. For instance, because it has a greater electron mobility than silicon, itsusesare numerous while that of silicon is limited. Transistors fabricated of this material can run at frequencies over 250 GHz. This transistor yields less noise when operating at the same high frequencies as its silicon counterparts. Gallium arsenide also has a higher breakdown voltage. By Breakdown voltage, it means the minimum (reverse) voltage applied that can make part of the component conduct electricity. Due to these factors, gallium arsenide has been a substantial material for several electrical applications ranging from the common to the extraordinary. Some of these include cellular telephones, satellites and satellite communication, micro and Nanoscale semiconductors, radar systems, and Nanobased solar power. One main reason why a solar cell is fabricated is for it to perform a specific task, which involves the production of electricity through the absorption of photons. When a light ray (radiant energy) from the sun, strikes the cell, some of it is absorbed within the semiconductor material (gallium arsenide). This means that the energy of the light absorbed is transferred to the aforesaid semiconductor. This energy excites the electrons, thereby enabling them to be free and attain a new energy state. In solar or photovoltaic cells, 
either of them consists of one or more electric fields that act as a mediator. This field is responsible for the liberation of electrons by absorption of light flowing in a specific direction thus current is generated. This current can be utilized by placing metal contacts on the top and bottom of the cell. With these newly placed contacts, the current can be drawn off to power any external appliance. In other to fabricate a GaAs solar or photovoltaic cell, synthesizing the GaAs crystal is the most paramount; otherwise, the solar cell will not be able to function. The three effective means of growing crystals include; Molecular Beam Epitaxy (MBE), Metal organic Vapour Phase Epitaxy (MOVPE), and Electrochemical Deposition (or Electroplating).

\section{Hybrid Solar Cell}

Hybrid solar cells conglomerate the advantages of both organic and inorganic semiconductors. They comprise of organic materials that consist of conjugated polymers that absorb rays of light as the donor and transport holes [30], while those that are made up of inorganic materials serve as the acceptor and electron transporter in the structure. This device has a potential for not only low-cost by roll-toroll processing but also for inaccessible solar power conversion. An organic material is mixed with a high electron transport material in the hybrid solar cells, to form the photoactive layer [31]. By assembling these two materials together in a heterojunctiontype photoactive layer, it can have greater power conversion efficiency than a single material. Amongst the two assembled materials, [32] one acts as the photon absorber and exciton donor while the other material assists exciton dissociation at the junction. The charge is transferred and then disconnected after an exciton created in the donor is delocalized on a donor-acceptor complex [33]. The required energy needed to isolate the exciton is provided by the energy offset between the LUMOs or conduction bands of both the donor and acceptor. Once dissociation is completed, the carriers are transported to the respective electrodes through a percolation network. An exciton can diffuse through a material at an average distance before annihilation by recombination is the exciton diffusion length. This is short in polymers, on the order of 5 to $10 \mathrm{~nm}$ [34]. The time scale for radioactive and non-radioactive decay is from 1 picosecond to 1 nanosecond [35]. Excitons created within this length close to an acceptor would add to the photocurrent. To be able to handle or deal with the problem of short exciton diffusion length, the use of a bulk heterojunction structure is preferable rather than a phaseseparated bilayer. Scattering the particles all 
over the polymer matrix creates a larger interfacial area for charge transfer to take place.

\section{Luminescent Solar Concentrator Cell (LSC)}

An LSC device is one that makes use of a thin sheet of material to capture solar radiation over a large area, before the energy via luminescent emission is been directed to cells mounted on the thin edges of the material layer. This material thin sheet characteristically consists of a polymer (such as poly-methyl methacrylate (PMMA), doped with radiant species such as quantum dots, organic dyes, or rare earth complexes [36]. The utmost purpose of designing and implementing the use of LSCs is to replace a large area of expensive solar cells in a standard flat-plate PV panel, with a cheaper alternative. Consequently, there will bea decrease in both the cost of the module $(E / \mathrm{W})$ and the solar power produced $(£ / \mathrm{kWh})$. The main advantage of LSC device is that it can capture both direct and diffuse solar radiation. Thus, tracking of the sun is not mandatory [37]. The aim of developing LSC is to create a working structure that achieves close to the theoretical maximum efficiency. The following properties are observed in an ideal LSC, they include; (i) It utilizes the solar spectrum efficiently as a result of broad absorption range. (ii) It shows $100 \%$ emission of light from the absorbing luminescent species. (iii) A large shift between the absorption and emission spectra to decrease absorption losses. (iv) Long-term stability [38]. A luminescent concentrator system with a collection of surface-embedded monocrystalline silicon solar $\mu$-cells (a) Diagrammatic illustration of a device, comprising of an array of solar microcells ( $\mu$-cells), a luminescent layer (LSC layer), a supporting, transparent substrate and a BSR. Usually, the device would direct the concentrated radiation on top of solar cells to generate electric power. Other configurations (such as coated or doped optical fibers or contoured stacks of alternating layers) may enhance its applications [39, 40]. The layers in the stack may be alternating strata or separate parallel plates in a solid structure. In principle, if the effective input area is adequately large relative to the effective output area, the output would be of similarly of greater irradiance than the input, as measured in watts per square meter. The ratio between the output and input irradiance of the entire device is known as the concentration factor. For instance, imagine a square glass sheet (or stack) 200 $\mathrm{mm}$ on a side, $5 \mathrm{~mm}$ thick. Its input area (e.g. the surface of one single face of the sheet oriented toward the energy source) is 10 times larger than the output area (e.g. the 
surface of four open edges) - 40000 square $\mathrm{mm}(200 \times 200)$ as compared to 4000 square $\mathrm{mm}(200 \times 5 \times 4)$. To a first approximation, the concentration factor of such an LSC device is proportional to the area of the input surfaces divided by the area of the edges multiplied by the efficiency of incoming light diverted towards the output area. Supposing that the glass sheet could divert incoming light from the face towards the edges with an efficiency of 50\%. The proposed sheet of glass in our example would give an output irradiance of light 5 times greater than that of the incident light, generating a concentration factor of 5 . In the same way, a graded refractive index optic fiber 1 square $\mathrm{mm}$ in cross-section, and 1 meter long, with a luminescent coating might demonstrate usefulness.

\section{Operational Principles and Structure of} Dye-Sensitized Solar Cell

\section{Structure of Dye-Sensitized Solar Cell}

\section{TiO2}

A porous layer of titanium dioxide $\left(\mathrm{TiO}_{2}\right)$ nanoparticles having wide bandgap suitable to generate a useful voltage. Titanium dioxide $\left(\mathrm{TiO}_{2}\right)$ exits in three forms i.e., rutile, anatase and brookite. Although rutile is more stable, crystalline anatases favoured as it is chemically more active in DSSCs [45]. The $\mathrm{TiO}_{2}$ is a semiconductor that has a wide band gap (Ebg $3.2 \mathrm{eV}$ ) [46]. It is low in cost, widely available, biocompatible, cheap, thermally stable, chemically inert and nontoxic. In atypical DSSC, the particle size of $\mathrm{TiO}_{2}$ anatase ranges $10-25 \mathrm{~nm}$ with a film thickness of 5-15 $\mu \mathrm{m}$. There are several alternatives to $\mathrm{TiO}_{2}$. Zinc oxide ( $\left.\mathrm{ZnO}\right)$ is a promising alternative to $\mathrm{TiO}_{2}$ because of its similar band structure and relatively high electron mobility. Shalini et al., prepared ZnO films on a conducting glass substrate showed an efficiency of $0.4 \%$. Higher electronic mobility of $\mathrm{ZnO}$ makes it more suitable for use in DSSC, but they have lesser lifetime due to the degradation of organic dyes under sunlight, increasing temperature, oxygen absorption, chemical change of electrodes and interface instability. Tin oxide $\left(\mathrm{SnO}_{2}\right)$ is another semiconductor oxide that has high mobility and large band gape. $3.8 \mathrm{eV}$ as compared to $\mathrm{TiO}_{2}(3.2 \mathrm{eV})$. It creates fewer oxidative holes in the valence band under ultraviolet light thereby reduce the dye degradation rate and improve the stability of DSSCs. More positive band edge position facilitates electron injection from photoexcited dye molecules. The performance of $\mathrm{SnO}_{2}$-based DSSCs has been observed far much less than that of $\mathrm{TiO}_{2}$ based ones. Particles of $\mathrm{TiO}_{2}$ that are used as a photoanode to absorb sunlight are well-known $n$-type semiconductor that provides more surface to adsorb dye, accept electrons from the excited dye and conducts 
them towards the external circuit [46].

\section{Dye}

A dye called as a sensitizer is covalently bonded to the surface of the mesoporous oxide layer to enhance light absorption. The dye acts as a molecular electron pump in DSSC by absorbing visible light, generating excited electrons and pumping them into the semiconductor. The sensitizers used in the DSSC can be divided into organic and inorganic. Inorganic dyes contain a transition metal in the structure. Polypyridyl ruthenium complexes had been regarded as the most efficient sensitizers and an overall light to electric power conversion efficiency $(\eta)$ of up to $11 \%$ was achieved by using N719 (Ditetrabutylammonium cis-bis( isothiocyanato)bis(2,2'-bipyridyl-4,4'-

dicarboxylato) ruthenium(II)) -based DSSCs. However, since ruthenium is a rare metal, it is expensive and environmental issues caused by the production of ruthenium complexes limits its applications. The dye must have certain properties to be suitable for application in DSSCs e.g. strong absorption in the visible range, high photo and thermal stability, good adsorption On the semiconductor's surface, that is, bonding strongly to the semiconductor surface with anchoring group, high solubility in the corresponding solvent, no toxicity, have a broad absorption spectrum in the visible range in order to capture solar radiation, a suitable high redox potential for regeneration followed by excitation[47, 48].Many organic dyes such as porphyrine, coumarines, perylenes, phthalocyanines, triaryl amines and carbazole have been paid great attention because of their modest cost, large molar absorption coefficients and satisfactory stability [49]. Organic dyes can be classified into donor-acceptor (D-A), donor-bridge-acceptor (D-B-A) and acceptor-bridge-acceptor (A-B-A) systems that have applications as electroactive and photoactive and photoactive materials in the field of molecular electronics; mainly photovoltaic Technologies [50]. Bonding to $\mathrm{TiO}_{2}$ surface has been achieved through functional groups such as salicylate, carboxylic acid, sulphonic acid, phosphoni cacid and acetylacetonate derivatives [51]. So, the functional group of $\pi$-extended dye is vital to adsorb on the surface of Carboxylic acids are the most extensively studied anchoring groups in porphyrin-sensitized solar cells. They promote strong electronic coupling between the energy levels of the excited sensitizer and the metal oxide, that results in fast and efficient electron injection.

\section{Electrolyte and Electrode}

An electrolyte, mostly iodide-tri-iodide, 
undergoes a redox reaction. The efficiency of DSSCs depends on the sensitizers, photoanode and counter electrode [52]. Also, the electrolyte is very important to determine cell performance. So the electrolyte is one of the key components in DSSCs. Electron injection depends on the electrolytes reducing ability. It provides internal electric ion conductivity by diffusing within the mesoporous $\mathrm{TiO}_{2}$ layer. Electrolyte contains a redox couple (such as $\mathrm{I}^{-} / \mathrm{I}_{3}^{-}$) that fills the space between the two electrodes. Based on their physical state, the electrolyte used in DSSC scan be divided into three types: liquid, quasi and solid. Liquid electrolytes could be divided into organic solvent electrolyte and ionic liquid electrolytes according to the solvent used. Iodide/triiodide-based liquid electrolyte being redox electrolyte has been the most widely used and efficient electrolyte [53, 54]. Platinum (Pt) is typically used as a counter electrode to catalyze the triiodide ions that are formed in the electrolytes by the reduction of iodide ions. Although Pt has higher energy conversion efficiencies, it has few limitations such as higher cost, instability in redox electrolyte, hightemperature sintering and resource scarcity. The open circuit voltage in DSSCs is determined by the energy difference between the fermi levels of the transparent conducting oxide (TCO) to the nanocrystalline $\mathrm{TiO}_{2}$ film and the counter electrode. An ideal counter electrode (CE) should have low electrical resistance and high electrocatalytic activity towards the iodide/triiodide redox reaction, being stable and transparent [46].

\section{Structure of Phthalocyanines}

Phthalocyanines (Pcs) are planar $18 \pi$ electron macroheterocycles that consist of four isoindole subunits linked together through nitrogen atoms [55]. Their extensively conjugated system generates intense absorption spectra, presenting two major bands: the $\mathrm{Q}$ and the Soret $\mathrm{B}$ band. The first, usually between $620-700 \mathrm{~nm}$ and origin of the green or blue color of the Pc, is the strongest, with molar absorptivity $(\varepsilon)$ values that exceed $105 \mathrm{~L} \mathrm{~mol}^{-1} \mathrm{~cm}^{-1}$. The Soret band lies near $350 \mathrm{~nm}$ and is generally much broader and less intense. Tailoring of the physical and optical properties of Pcs can be achieved either by addition of a metal into the ring or by axial and/or peripheral substitution with a variety of ligands. In addition, their redox properties are suitable both for sensitization of $\mathrm{TiO}_{2}$ films and for dye regeneration by the electrolyte. A further substantial detail is their thermal and chemical stability. All these key points render Pcs promising candidates for incorporation in DSSCs, representing ideal light-harvesting systems for light-to-energy 
conversion devices. However, despite the refined characteristics of these macrocycles, the conversion efficiencies attained by phthalocyanine-sensitized solar cells have not yet been able to match the values obtained by porphyrin-based devices, even though there has been remarkable progress in recent years [56]. The development of Pcs has been hindered by a strong tendency towards aggregation on the semiconductor surface, more pronounced in Pcs than in porphyrins, due to their more $\pi$ - extended system.

\section{Derivatives of phthalocyanines}

The type of DSSCs based on phthalocyanines as light-harvesters were not able to surpass $1 \%$ overall efficiency and this due to the aggregation of the dye on the metal oxide semiconductor surface, resulting in nonradiative deactivation of the dye in the excited state, in combination with lack of directionality of the symmetrical dyes and poor coupling of the LUMO with the $\mathrm{TiO}_{2}$ conduction band [57]. In other to overcome this drawback there is a need for a substituent to increase the efficiency of the solar cell. Thiochalcone substituted phthalocyanines for dye-sensitized solar cells metallophthalocyanines $(\mathrm{M}=\mathrm{Zn}$, Co, $\mathrm{Ni}$ ), metallophthalocyanines are known for their excellent thermal stability, optical, photophysical, photochemical and electrochemical properties, they have been utilized in dye-sensitized solar cells (DSSCs) [58] photosensitizers in photodynamic therapy[59], catalysts [60], non-linear optics [61], chemical sensors [62], light emitting diodes [63], liquid crystals [64] and electrochemical applications [65]. Also, they have attracted special attention because of their intense absorption bands in the red/near-infrared (NIR) region and high extinction coefficients due to planar structure and large $\pi$-structure [66]. A new peripherally tetra-substituted metallophthalocyanines (MPcs, M = Zn, Co, $\mathrm{Ni}$ ) bearing the chalcone, (E)-3-(4hydroxyphenyl)-1-(thiophen-2-yl)prop-2en-1-one, for dye-sensitized solar cells (DSSCs) were synthesized. It was reported that the Zn(II) (4), Co(II) (5) and Ni(II) (6) metallophthalocyanines (MPcs) which were synthesized and characterized are substituted with thiochalcone group on peripheral positions. The synthesized MPcs were soluble in different organic solvents. The combined optical and electrochemical studies suggested that the HOMO and the LUMO energy levels of the complexes are suitable for use as sensitizers in dyesensitized solar cells (DSSCs). It was also found that the photovoltaic properties of these MPcs were affected by the central metal ions. The DSSCs based on 4 and 6 sensitizers showed power conversion 
efficiencies of $1.27 \%$ and $1.11 \%$, respectively, whereas the cell based on $\mathbf{5}$ exhibited lower efficiency (0.51\%). This can be attributed to the different energy level of Co in the ring than those of other sensitizers, which may reduce the electron transfer in $\mathbf{5}$. These results reveal that thiochalcone substituted symmetric ZnPc and NiPc can be promising candidates as sensitizers for use in DSSCs.

\section{Structure of porphyrin}

Porphyrin sensitizers have attracted a great deal of attention in solar cells as they are cheap, easy to synthesize and modify, stable [67], less toxic [68, 69], rigid geometry, the ability to coordinate metals, efficient electron transfer [70] etc. They also possess high molar absorption coefficients [71] and excellent light harvesting potential. Porphyrins absorb visible and near-infrared (NIR) region of the solar spectrum i.e., Intense Soret absorption band (400-450 $\mathrm{nm}$ ) in the blue region and moderate $\mathrm{Q}$ absorption bands (500-650 $\mathrm{nm}$ ) in the red region [69, 72-73]. The energy of LUMO orbitals of porphyrin is above the conduction band of TiO2while its HOMO level is below the redox couple of the electrolyte solution [74]. Porphyrins (Pors) are macrocycles consists of four pyrrole rings fused together. They are highly conjugated systems of 20 carbons and 4 nitrogens. It has $18-\Pi$ electrons that make them aromatic. The acidic $\mathrm{NH}$ protons located inside the porphyrin ring can be deprotonated to yield the porphyrinato anions. These rigid and planner dianion species with a central cavity exhibits remarkable ligation characteristic towards metal cations [75]. Porphyrin molecules are used in various applications such as chemical and biological sensors in addition to DSSC, transistor and organic light emitting diodes. The properties of porphyrin sensitizers can be tuned by modifying their donor, П-conjugate-bridge and acceptor. Charge separation is an important factor that affects solar cell efficiency. It is formed in photoinduced charge transfer between the donor and acceptor [76]. When the donor absorbs light energy, it injects an electron into the LUMO of the acceptor [77].

\section{Derivatives of porphyrin}

A meso-substituted carboxylic acid Znporphyrin molecule was synthesized, the molecule has a soret band at $427 \mathrm{~nm}$ and Q bands at $559 \mathrm{~nm}$ and $606 \mathrm{~nm}$, and Its absorption peak is broad and strong in the range of $300-750 \mathrm{~nm}$. It is attributed to the extended conjugation of $\Pi$-systems in the meso-positions of porphyrin.

The oxidation potential of synthesized molecules was $0.29 \mathrm{eV}, 0.32 \mathrm{eV}, 0.34 \mathrm{eV}$ 
respectively. It is probably due to the more effective conjugation of the double bond in 12 with the porphyrin core than that of the benzo group in 10 [44].

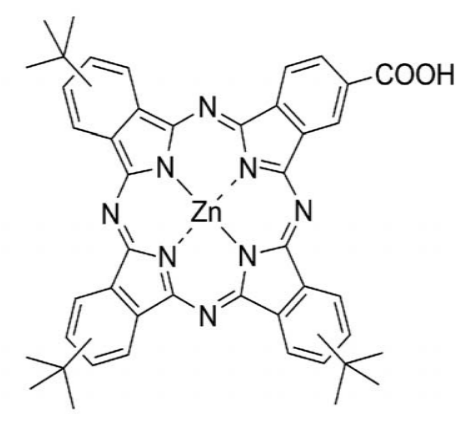

Figure 4. ZnPc stucture

Three porphyrin derivatives include long alkoxy chains attached to the ortho positions of the phenyl ring and a phenyl carboxylate acid or acrylic acid at the meso position. All porphyrin molecules were based on П-Aporphyrin system. The phenyl group at meso position is a conjugative linkage between the porphyrin and the binding group carboxylic acid. It is responsible to improve light harvesting performance. Arteaga et al. [50] have synthesized a series of new porphyrin molecules as well as their application in dye-sensitized nanocrystalline $\mathrm{TiO}_{2}$ solar cells. The dyes exhibit strong Soret bands at 439-454 nm and weak Q bands between 574 and 664 . Intramolecular charge transfer bands (ICT) occurred between the porphyrin core donor unit and the electron acceptors. An additional band around $350 \mathrm{~nm}$ corresponds to the $\Pi-\Pi^{*}$ transition was also found. The thiophene containing dyes 15-17 exhibit red-shifted when compared to the corresponding fluorene derivatives 18-20. This is attributed to the enhanced electronic coupling between the donor and acceptor entities in 15-17 due to the thiophene unit, which provides better conjugation than the fluorene moiety and lowers the energy of the charge transfer for conjugated dipolar molecules. The HOMO energy level of the dyes have potentials ranging from 0.73 to $0.76 \mathrm{~V}$, which are higher than that of the redox couple $(\sim 0.40 \mathrm{~V})$. The LUMO energy levels of the dyes range from -1.07 to -1.20 $\mathrm{V}$, lower than the energy level of the CB (conductive band) of $\mathrm{TiO}_{2}(\sim-0.5 \mathrm{~V})$, with the energy gap of $0.57-0.70 \mathrm{~V}$. It is well known that an energy gap of $0.2 \mathrm{eV}$ is necessary for efficient electron injection. DSSCs based on the dyes bearing a cyanoacrylic acid acceptor group showed the best photovoltaic performance and corresponds to an overall conversion efficiency of 5.56 and $4.13 \%$, respectively. Diphenylamine Zn(II) porphyrin behaves as core electron donor unit while the cyanoacrylic acid, rhodanine acetic acid, and dicyanorhodanine are acceptors.

\section{Conclusion}

Series of porphyrins which were synthesized, especially zinc complexes, have 
been used in DSSC preparation. Their LUMO energy levels are above the conduction band of the $\mathrm{TiO}_{2}$ while HOMO energy levels are below the redox couple in the electrolyte solution and it requires a charge separation at the $\mathrm{TiO}_{2} /$ dye/electrolyte surface. It has been observed that Metal free-porphyrin has low photovoltaic conversion efficiency than zinc-porphyrins. Porphyrins generally show lower performance due to the limited light absorption, poor matching to solar light distribution and consequently possess a low value of short circuit current. Generally, two methods are used to increase their performance i.e., elongating the $\Pi$ system and lowering the symmetry of the macrocycle, which can lead to a significantly broadened Soret band and red shifted Q band absorptions. DSSC devices using porphyrin sensitizers with the linker and anchor units functionalized at the $\beta$-position is reported to show a value as high as 7.1\%.Metallophthalocyanines (MPcs) have been synthesized and characterized which are substituted with thiochalcone group on peripheral positions. All synthesized MPcs were soluble in different organic solvents. The combined optical and electrochemical studies suggested that the HOMO and the LUMO energy levels of the complexes are suitable for use as sensitizers in dyesensitized solar cells (DSSCs). It was also found that the photovoltaic properties of these MPcs were affected by the central metal ions. The DSSCs based on three metals substituted which are $\mathrm{Zn}, \mathrm{Ni}$ and Co. it was shown that $\mathrm{Zn}$ substituted metallophthalocyanines is the most efficient with efficiency power conversion of 1.27.

\section{References}

[1].http://www.chemistryexplained.com/R $\underline{\mathrm{u}-\mathrm{Sp} / \text { Solar-Cells.html }}$

[2]. L. Eldada, Thin film CIGS photovoltaic modules: monolithic integration and advanced packaging for high performance, high reliability and low cost. Optoelectronic Integrated Circuits XIII. International Society for Optics and Photonics, 2011, 7942, 79420F.

[3].T. Tanti, World economic forum annual meeting, 2018. https://www.weforum.org/agenda/2018/ 01/clean-energy-renewable-growthsustainable-key-trends/

[4]. M.B. Askari, M. Mirzaei, V. Abadi and M. Mirhabibi, American Journal of optics and Photonics, 2015, 3, 94-113.

[5]. I. Norris, Synthesis and Characterisation of Chiral Conducting Polymers, A Thesis presented to the Department of Chemistry University of Wollongong, 1999, pp. 1-15.

[6]. P.N. Ciesielskia, F.M. Hijazib, A.M. Scott, C.J. Faulkner, L.Beard, K. Emmett, S.J. Rosenthal, D. Cliffel, G.K. Jennings, 2010, 3047-3053. 
[7]. O. Yehezkeli,, R. Tel-Vered, J. in a Glass-to-Glass Sealed PV Module, Wasserman, A. Trifonov, D. Michaeli, R. Vitreous State Laboratory, and AMELIO Nechushtai, I. Willner, Nature communicat., $\quad$ Solar, Inc. 2011.

2012.

[8]. Wohlgemuth J.H., Narayanan S. Twenty [18]. H. Trabish, The Lowdown on the Safety Second IEEE Photovoltaic Specialists Conference. 1991, 1, 273-277.

[9]. "Publications, Presentations, and News Database: Cadmium Telluride". National Renewable Energy Laboratory.

[10]. K. Zweibel, J. Mason, V. Fthenakis, "A Solar Grand Plan", Scientific American, Jan 2008.

[11]. Further mention of cost competitiveness: Scientific American, April 2008.

[12]. J. Peng, L. Lu, H. Yang, Renewable and Sustainable Energy Reviews, 2013, 19, 255274.

[13]. V. Fthenakis, H.C. Kim, Renewable and Sustainable Energy Reviews, 2010, 14, 20392048.

[14]. M.J. de Wild-Scholten, Solar Energy Mater. Solar Cells, 2013, 119, 296-305.

[15]. Fthenakis, Vasilis M. (2004). Archived from the original on 23 September 2014.

[16]. Werner, Jürgen H. (2 November 2011). Archived from the original (PDF) on 23 September 2014. Retrieved 23 September 2014.

[17]. Water Solubility of Cadmium Telluride of First Solar's CdTe Thin Film, greentechmedia.com March 19, 2012

[19]. R. Mullins, Cadmium: The Dark Side of Thin-Film, September 25, 2008

[20]. Supply Constraints Analysis, National Renewable Energy Laboratory

[21]. Fraunhofer ISE Photovoltaics Report, July 28, 2014, 18-19.

[22]. http://www.solar-facts-andadvice.com/amorphoussilicon.html

[23]. http://www.iea.org (2014. Retrieved 7 October 2014.

[24]. Fraunhofer ISE and NREL (January 2015). Retrieved 25 April 2015.

[25]. "DOE Solar Energy Technologies Program Peer Review" (PDF). U.S. department of energy 2009. Retrieved 10 February 2011.

[26]. Wan, Haiying "Dye Sensitized Solar Cells", University of Alabama Department of Chemistry, p. 3

[27]. Dye-Sensitized vs. Thin Film Solar Cells, European Institute for Energy Research, 30 June 2006.

[28]. H. Tributsch, Coordinat. Chem. Rev., 2004, 248, 1511.

[29]. S.J. Moss, A. Ledwith, The Chemistry of 
the Semiconductor Industry, Springer, 1987.

[30]. D.J. Milliron, I. Gur, A.P. Alivisatos, Hybrid Organic-Nanocrystal Solar Cells. MRS Bulletin, 2005, 30: 41-44.

[31]. S.E. Shaheen, D.S. Ginley, G.E. Jabbour, Organic-Based Photovoltaics. MRS Bulletin, 2005, 30, 10.

[32]. B.R. Saunders, M.L. Turner, Advances in Colloid and Interface Science, 2008, 138, 123.

[33]. N.S. Sariciftci, L. Smilowitz, A.J. Heeger, F. Wudl, Synthetic Metals, 1993, 59, 333352.

[34]. D.S. Ginger, N.C. Greenham, Physical Review B, 1999, 59,624-629.

[35]. P.E. Shaw, A. Ruseckas, I.D.W. Samuel, Advanced Materials, 2008, 20, 3516-3520.

[36]. M.G. Debije, P.P.C Verbunt, P.J. Nadkarni, S. Velate, K. Bhaumik, S. Nedumbamana, B.C. Rowan, B. S. Richards, T.L. Hoeks, Applied Optics, 2011, 50, 163169.

[37]. M.G. Debije, P.P.C. Verbunt, B.C Rowan, B.S Richards, T.L Hoeks. Applied Optics, 2008, 47, 6763-6768,.

[38]. R. Reisfeld, S. Neuman, Nature, 1978, 274, 144-145.

[39]. R. Reisfeld, Y. Kalisky, Nature, 1980, 283, 281-282.

[40]. A. Nwanya, F. Ezema, P. Ejikeme,
International Journal of the Physical Sciences, 2011, 6, 5190-5201.

[41]. Ö. Birel, An overview on the some phenotiazıne derıvatıve molecules used in organic dye-sensitızed solar cells. Electronic Journal of Vocational Colleges, 2015.

[42]. M. Xie, J. Wang, J. Ren, L. Hao, F.Q. Bai, Q.J. Pan, Org. Electron., 2015, 26, 164-175.

[43]. P.A. Angaridis, T. Lazarides, A.C. Coutsolelos, Polyhedron, 2014, 82, 19-32.

[44]. J. Gong, J. Liang, K. Sumathy, RenewSust Energ Rev, 2012, 16, 5848-5860.

[45]. S. Shalini, R.B. Prabhu, S. Prasanna, T.K. Mallick, S. Senthilarasu, Renew. Sust. Energ. Rev., 2015, 51, 1306-1325.

[46]. N. Zhang, B. Zhang, J. Yan, X. Xue, X. Peng, Y. Li, Renew Energy, 2015, 77, 579585

[47]. C. Grätzel, S.M. Zakeeruddin, Materials Today, 2013, 16, 11-18.

[48]. Z. Zeng, B. Zhang, C. Li, X. Peng, X. Liu, S. Meng, Dyes Pigments, 2014, 100, 278-285. [49]. D. Arteaga, R. Cotta, A. Ortiz, B. Insuasty, N. Martin, Echegoyen L, Dyes Pigments, 2015, 112, 127-137.

[50]. W.M. Campbell, A.K. Burrell, D.L. Officer, K.W. Jolley, Coord. Chem. Rev., 2004, $248,1363-1379$.

[51]. J. Lu, S. Liu, Y. Shen, J. Xu, Y. Cheng, M. Wang, Electrochim. Acta., 2015, 179, 187196 
[52]. Sengupta D, Das P, Mondal B, Mukherjee K 0 Renew Sust Energ Rev, 2016, 60, 356-376.

[53]. F.T. Kong, S.Y. Dai, K.J. Wang Advances in Opto Electronics, 2007.

[54]. a) G. de la Torre, C.G. Claessens, T. Torres, Chem. Commun. 2007, 2000-2015;

b) J. Mack, N. Kobayashi, Chem. Rev., 2011, 111, 281-321; c) C.G. Claessens, U. Hahn, T. Torres, Chem. Rec. 2008, 8, 75-97.

[55]. M.V. Martínez-Díaz, T. Torres, Handbook of Porphyrin Science (Eds.: K. M. Kadish, K.M. Smith, R. Guilard), Academic Press, Singapore, 2010, vol. 10, pp. 141181; b) M.V. Martínez- Díaz, G. de la Torre, T. Torres, Chem. Commun. 2010, 46, 70907108; c) M.V. Martínez-Díaz, M. Ince, T. Torres, Monatsh. Chem. 2011, 142, 699-707. [56]. a) V. Velkannan, Curr. Sci. 2012, 102, 991-1000; b) M.G. Walter, A.B. Rudine, C.C. Wamser, J. Porphyrins Phthalocyanines

2010, 14, 759-792.

[57]. a) M.K. Nazeeruddin, R. HumphryBaker, M. Grätzel, D. Wöhrle, G. Schnurpfeil, G. Schneider, A. Hirth, N. Trombach, J. Porphyrins Phthalocyanines 1999, 3, 230237; b) J. He, G. Benkö, F. Korodi, T. Polivka, R. Lomoth, B. Åkermark, L. Sun, A. Hagfeldt, V. Sundstrom, J. Am. Chem. Soc. 2002, 124, 4922-4932.

[58]. J.J. Cid, M. Garcia-Iglesias, J.H. Yum, A.
Vazquez, M. Gratzel, M.K. Nazeeruddin, E. Palomares, T. Torres. Chem. Eur. J., 2009, 15, 5130.

[59]. N. Nwahara, J. Britton, T. Nyokong. J. Coord. Chem., 2017, 70, 1601.

[60]. H. Karaca. J. Organomet. Chem., 2016, 822, 39.

[61]. G. Martin, M.V. Martinez-Diaz, G. de la Torre, I. Ledoux, J. Zyss, F. Agullo-Lopez, T.

Torres. Synth. Met., 2003, 139, 95.

[62]. H. Karaca, B. Çayeğil, S. Sezer. Synth. Met., 2016, 215, 134.

[63]. C.L. Wu, Y. Chen. Opt. Mater., 2017, 69, 38.

[64]. J.F. Van Der Pol, E. Neeleman, J.W. Zwikker, R.J.M. Nolte, W. Drenth, J. Aerts, R.

Visser, S.J. Picken. Liq. Cryst., 1989, 61, 557.

[65]. H. Karaca, S. Sezer, Ş. Özalp-Yaman, C. Tanyeli. Polyhedron, 2014, 72, 147.

[66]. A. Hagfeldt, G. Boschloo, L.C.L. Kloo, H. Pettersson. Chem. Rev., 2010, 110, 6595.

[67]. X. Zhang, Q. Chen, H. Sun, T. Pan, G. Hu, R. Ma, Spectrochim Acta A Mol Biomol Spectrosc, 2014, 118, 564-571

[65]. D. Daphnomili, G. Sharma, S. Biswas, K.J. Thomas, A. Coutsolelos, J Photochem Photobiol A Chem, 2013, 253, 88-96

[66]. J. Mikroyannidis, G. Charalambidis, A. Coutsolelos, P. Balraju, G. Sharma, J Power Sources, 2011, 196, 6622-6628.

Forneli, J. Albero, E. Martinez-Ferrero, P. 
[67]. V.K. Narra, H. Ullah, V.K. Singh, L. Giribabu, S. Senthilarasu, S. Z. Karazhanov, 2015, 100, 313-320.

[68]. B. Chen, L. Sun, Y.S. Xie, Chin. Chem.

Lett., 2015, 26, 899-904

[69]. C. Chitpakdee, S. Namuangruk, K. Suttisintong, S. Jungsuttiwong, T. Keawin, T.

Sudyoadsuk, Dyes Pigments, 2015, 118, 6475.

[70]. W. Zhou, B. Zhao, P. Shen, S. Jiang, H. Huang, L. Deng, Dyes Pigments, 2011, 91, 404-412

[71]. G. Sharma, G. Zervaki, P. Angaridis, A. Vatikioti, K. Gupta, T. Gayathri, Org Electron, 2014, 15, 1324-1337.

[72]. A. Shalabi, A. El Mahdy, H. Taha, K.
Soliman, J Phys Chem Solids, 2015, 76, 22-33

[73]. G.D. Sharma, P.A. Angaridis, S. Pipou, G.E. Zervaki, V. Nikolaou, R. Misra,

Org Electron, 2015, 25, 295-307.

[74]. K. Sirithip, S. Morada, S, Namuangruk, T. Keawin, S. Jungsuttiwong, T. Sudyoadsuk, Tetrahedron Lett, 2013, 54, 2435-2439.

[75]. M.S.A. Alvarado, Novel porphyrin for DSSC and BHJ solar cells, 2015.

[76]. C.R. Zhang, L.H. Han, J.W. Zhe, N.Z. Jin, Y.L. Shen, J.J. Gong, Computational and Theoretical Chemistry, 2014, 1039, 62-70.

[77]. M.P. Balanay, C.V.P. Dipaling, S.H. Lee, D.H. Kim, K.H. Lee, Sol Energy Mater Sol Cells, 2007, 91, 1775-1781.

How to cite this manuscript: Oyebanji Opeyemi, Hitler Louis*, Chinanso Opara, Oyebanji Funmilayo, Thomas Magu*, Porphyrin and Phthalocyanines-Based Solar Cells: Fundamental Mechanisms and Recent Advances, Adv. J. Chem. A, 2019, 2(1), 21-44. 